and after a few days longer the cicatrization begun. In children, in particular, I obtained very striking results, and there was not the least doubt, that the effect must be ascribed to the phosphate of lime. Generally I ordered it to be taken with the breakfast, dinner, and supper, in order to have it mixed as well as possible with the food taken; it is certain, that the phosphate of lime easily dissolves in albuminous solutions as well as in mineral acids, and in the acid of the stomach. But I have especially to mention, that in several cases, some time after leaving off the use of the phosphate of lime, I observed a fresh outbreak of the ulcers, for the real cause of which circumstance I could scarcely account at the time; I only supposed that the bad living of the patients, the food exclusively consisting of potatoes and bread, the abode in a damp unhealthy air, \&c., caused the continuance of the general dyscrasia, and the repeated breaking out of the local affection. I am able now to account for it better than I could before, and with respect to this point, I must refer to the following parts of these communications.

As most of these ulcers occurred in patients afficted with scrofula, the question arose, whether the phosphate of lime really cured the scrofulous dyscrasia, or only a part of it. With regard to this point from many observations, the number of which has much increased since, it resulted that there exists an undoubted intimate relation between scrofula and want of phosphate of lime, but that we are not able to cure the dyscrasia by the mere use of the phosphate. The same is the case with tuberculosis, a disease which is well known to be intimately related to, if not identical with, scrofula. In both kinds of disease, however, we shall promote the cure in the most efficient manner by the administration of the phosphate of lime, and I cannot forbear recommending its use as much as possible. In the following pages I shall give the explanation of these facts, which $I$ hope will at once prove, that the effect of the phospliate ought to be such an one as $I$ imagined and really found it to be. I have especially to mention, that the waste of tissues, or, in other words, the want of formation of cells, was apparently less in many cases of tuberculosis and scrofula, which were treated with phosphate of lime, besides other remedies, than in those which were treated without the phosphate; that the cure of tuberculous ulcers of the intestines was evidently promoted and even effected by the administration of the phosphate, and this remedy proved most efficient in cases of incipient acute tuberculosis, and even those which are well known to manifest at their commencement nearly all the symptoms of typhus. I need not enter here more deeply npon the special effects of the administration of the phosphate in these cases, if the one general fact is always kept in mind, that it increases the formation of cells, or prevents the rapid and fearful waste of tissues.

In accordance with those facts, the phosphate of lime proved most beneficial in children who suffered from scrofula, diarrhœa, ulcerations and excoriations of the skin and the bowels, general waste of the cellular tissue, loss of power, \&c. In these cases, the mere use of six to ten grains per diem was often quite sufficient to effect the cure, and $I$ have met with such striking and satisfactory results, as to leave no doubt that the want of the phosphate of lime was the real cause of the symptoms alluded to. These results, too, are confirmed by many physiological observations. Chossat, for instance, observed that pigeons, in consequence of an artificial want of phosphate of lime in their food, became afflicted with diarrhoea and softening of the bones; children, in the period of dentition, or when afflicted with rickets, which disease positively shows a want of phosphate of lime, are especially well known to suffer from diarrhœa, sores, \&c. Still I have to mention the interesting observation, that in patients who were afflicted with diseases, in which the phosphate of lime proved beneficial, and who consequently were supposed to suffer from a want of phosphate of lime in their economy, wounds of occasionally applied blisters healed much more slowly than was the case in other patients, and the more so the more distinctly those symptoms appeared which should be referred to a want of phosphate of lime.

In syphilis $I$ also tried the phosphate of lime, and even in persons who had for a long time already suffered from secondary ulcers, ulcers of the bones, \&c., and became emaciated and extremely weak during that time. These cases likewise showed a most beneficial effect of the phosphate on the formation of cells. It ought to be mentioned, that besides the phosphates, the iodide of mercury was administered, but I never have met with such a rapid cicatrization of syphilitic ulcers, as was the case in these persons, and I could not help thinking that the cure was promoted in a remarkable degree by the internal exhibition of the phosphate. With respect to this point, I have drawn attention to the relation between scrofula and syphilis, and I think there are many symptoms in both of these diseases, and many facts besides, which evidently show an intimate relationship between them, and require a more accurate study than has been given to them hitherto.

As to other affections, in which I have tried the phosphate of lime, I have to mention rickets, caries, inflammations, and consecutive abundant suppurations of the cellular tissue, and also fractures of the bones. In all these cases, the administration proved most beneficial, and I would strongly advocate its further experimental use. With respect to fractures of the bones, I have to state in particular, that the consolidation of the callus took place in a much shorter period than is generally the case; however, too large doses of phosphate of lime must be shunned in these cases, as I have observed an abundant callus, causing a deformity of the bones, produced by the daily administration of twenty-four grains of the phosphate for a fortnight.

With regard to the fact that phosphoric acid is always produced in the economy by the changes of albuminous substances, and supposing that this phosphoric acid might combine with the lime, if carbonate of lime has been given, I tried also the carbonate; but the results of its administration were not so favourable as those which followed the administration of the phosphate, unless in some cases where the urine presented a high degree of acidity. This even was the case in many children afflicted with scrofula, and it must be decided by future experiments, whether the carbonate of lime is preferable to the phosphate in these patients.

\section{ON A SUCCESSFUL CASE OF TRANSFUSION.}

By G. BELLASIS MASFEN, EsQ. HOUSE-SURGEON TO THF STAFFORDSHIHE INFYRMARY.

ON the 30th of July, 1848, at one P.M., I was called in to attend Mrs. B-, a lady of particularly delicate appearance, in her thirty-eighth year. It appears that on the evening of the 29th she had perceived some slight sanguineous discharge from the vagina, and had consulted my father, to whom she described herself as being four nionths advanced in her tenth pregnancy, but thought that the clild had not grown for the last month or two. He ordered a mixture containing diluted sulphuric acid with Battley's sedative; but the discharge continued to increase until about seven o'clock this morning, when it became quite alarming. Plugging and injections of oakbark were tried, but with no effect, and a dose of ergot was administered, which produced a severe pain, and the expulsion of a two-months' foetus; but the hæmorrhage continued to increase till one P.M., when I first saw her.

I found her excessively weak, from loss of blood; not the slightest pulse was to be felt at the wrist; and she became at last insensibie. The stomach rejected everything, and though the hæmorrhage had in a great measure stopped, there was every symptoin of sinking and speedy dissolution.

About three o'clock, it being the opinion of every one present that it was the only possible means of saving her life, the operation of transfusion was decided upon, which I performed in the presence of Dr. Knight and my father. I immersed a four-ounce brass syringe in water at the temperature of $110^{\circ}$ Fahr., and drew a full stream of blood into it from the arm of a stont buxom-looking servant-maid. This I injected into a vein on the left arm, taking every precaution to prevent the admission of any air-bubbles. As the operation was going on, consciousness appeared to be somewhat roused, and the pulse became slightly perceptible at the other arm, but in the course of half an hour the pulse lad again disappeared, and she remained still unconscious. I then a second time injected three ounces of blood into the right arm, (the veins were so smail and empty that there was difficulty in finding the same opening twice; this was again attended with a return of pulse and sensibility, which, however, gradually disappeared as before. After an interval of nearly an hour, I injected a third three ounces of blood, which produced more permanent good effects; the pulse gradually rose as the injection went on, colour made its appearance in her face, and she inquired if we had been bleeding her. During the evening she complained much of thirst, and she had occasionally a teaspoonful of wine-and-water.- Eight P.M.: The pulse was slightly perceptible, but was not to be counted; she attempted to take a cup of tea, but it was inmediately rejected, as was also even a teaspoonful of water, and she 
remained all night awake and thirsty, but afraid to drink even a little water.

31st.-Six A.M.: The pulse was 150 , and very much increased in strength; the tongue dark-brown, hard, and dry. Ordered three drops of creosote in form of a pill. She vomited almost immediately after taking it, but did not throw up the pill, which from that time appeared to allay the sickness. She then took a table-spoonful of brandy-mixture every hour. In the evening she still complained of thirst, and was ordered the following mixture:-Sesquicarbonate of soda, two and a half drachms; sesquicarbonate of ammonia, half a drachm; compound tiucture of cardamoms, two drachms; oil of lemon, six drops; distilled-water to six ounces. Two table-spoonfuls to be taken every three or four hours in a state of effervescence, with twelve grains of citric acid. There was great extravasation of blood for six or eight inches above and below the elbow in both arms, probably the effect of the injection. Ordered warm-water dressing.

August 1st \& 2nd.-She continued gradually improving in appearance; her pulse was slower, and she was better able to take slight nourishment. The arms were becoming more ecchymosed, and she complained of great pain in them. The warm-water dressing was continued.

3rd.- - Her health is gradually improving, and she is taking no medicine; complains of great pain in the right arm, which was much inflamed, and very hard just below the elbow, and seemed likely to suppurate. Ordered castor-oil and the water-dressing

4th.-The arms rather better; the swelling abated.

5th.-Continues to improve, both in health and as regards her arms. Ordered tincture of sesquichloride of iron, one drachm; infusion of quassia and camphor mixture, of each three ounces; to take two table-spoonfuls three times a day.

14th.-The arms have been gradually improving, and the discoloration is nearly gone, but they remain very weak, and she is not able to write.

28 th.-She has now quite recovered the use of her arms, and is in general good health. From this time I discontinued attendance.

In June, 1819, she miscarried again, but otherwise she has remained perfectly well up to the present time.

\section{Tigospital aReports.}

\section{SOUTH STAFFORDSHIRE GENERAL HOSPITAL, WOLVERHAMPTON.}

(Reported by Jorn Tornam, M.D. Lond., Physician to the Hospital.

Successful Employment of Kosso in Two Cases of Tania Solium.

THE two following cases afford additional testimony to the efficacy of the brayera anthelmintica as a vermifuge in cases of tape-worm.

As the efficiency of every remedy is greatly dependent upon its freedom from adulteration, I may state that the specimen of kosso employed by me was kindly presented to me by $\mathrm{Mr}$. R. Sandford, surgeon, of Baschurch, who himself procured it, during his residence in Jerusalem, from an Abyssinian merchant.

A scruple and a half of the powdered kosso was infused in four ounces of warm water, allowed to stand for half an hour, and then, having been stirred up with a spoon, the whole was swallowed at once.

A similar dose was given at eleven o'clock the same morning, to each of two young women, both of whom had a short time previously passed portions of tape-worm; and the patients were detained in the hospital for the remainder of the day, in order that the effects of the medicine might be observed, which were, nansea and sensation of thirst, followed by catharsis, and the expulsion of a quantity of tænia solium. In one case, only a few inches of the parasite came away; in the other, some eighteen or twenty feet; and in both instances the heal of tire animal was evacuated.

There had been no previous treatment by cathartics, or other medicntion.

I had only once previously employed this remedy, in place of the ordinary mixture of turpentine and castor-oil, and in this instance the alvine evacuations were by some mistake thrown away, so that no direct evidence of the expulsion of the parasite could be obtained; but the symptoms of which the patient complained have never recurred. The dose then given was half an ounce, but this prodnced violent purging. The small quantity administered in the other two instances appears to have becn quite effectual, and also produced catharsis, as the brayera anthelmintica does when taken in its native locality, by the inhabitants of Abyssinia; who, as my friend Mr. Sandford remarks, in a note which accompanied his present of kosso, "never travel without it; and they require a large dose, as they will eat eighteen pounds of raw meat at one meal." But we learn from Johnston's Travels in Abysinia, that the administration of these large quantities is not without its ill effects, for he says,- " Even men have been known after a large dose to have died the same day from its consequences - no civilized stomach could bear the bulk of the drug necesary to produce its effects."

Dr. Pereira states the dose for an adult to be half an ounce, infused for ten minutes in ten ounces of lukewarm water.(Pharmaceutical Journal, July 1, 1850.)

March 21, 1851 .

\section{fforeign 进epartment.}

Case of Poisoning by Laudanum, resulting from a Mistake in a Physician's Prescription.

A CASE which has caused much sensation among the profession at Paris, was lately tried before the tribunal correctionel. The facts are briefly these:-In October, 1850, a Mr. Labbé, a post-master at Alfort, near Paris, was attended for a severe indisposition, by Dr. Deguise, a highly respected practitioner of the French capital. In the course of the treatment, Dr. Deguise prescribed an injection with laudanum, and instead of writing ten drops, wrote ten grammes. (The gramme is equivalent to about fifteen grains.) The patient was soon afterwards thrown into a comatose state; but by proper treatment was completely roused, and remained quite conscious, and free from narcotic symptoms, for twenty hours. After this period he, however, suddenly grew worse, and died two days after the injection had been administered.

The authorities appointed three commissioners, Messrs. Cruveilhier, Devergie, and Rayer, to investigate the matter. The result of the inquiry was, that the commissioners were of opinion, that the patient had died of a low fever, complicated by an overdose of laudanum. The court, not seeing in this answer whether the death had resulted from the imprudence of the medical attendant or not, disregarded the verdict of the commissioners, (without ordering a post-mortem examination, ) and put Dr. Deguise on his trial. The most eminent men of the faculty were examined, among whom was Orfila, the points of interest being the quantity of laudanum injected, and the period (twenty hotrrs) during which lucidity had been regained. The medical testimony was mainly in support of the commissioners' opinion, but the court found the accused guilty of homicide by imprudence, and fined him four pounds, with costs. The laudanum used was the preparation which goes by the name of Sydenham's laudanum, or compound opium-wine of the Parisian codex. We shall just transcribe its composition: Opium, two ounces; saffron, one ounce; cinnamon and cloves, of each, one drachm; malaga wine, one pound. Twenty drops contain one grain of opium.

Forced Dilatation in Stricture of the Rectum.

M. Drevlofor advocates, in L'Union Medicale, the ase of wooden dilators, resembling rolling-pins, with one end somewhat swelled, to conquer strictures of the rectum. He really does conquer them in a very effective manner, for he forcibly pushes through the stricture with the thick end of the dilator, and goes on pushing and tearing with gradually increasing sizes, until he has in two or three sittings destroyed the stricture... and the gut.

\section{Incision of the Vulva as a Preventive Measure against Ruptured Perinceum.}

M.PAUL DoBors, and lately M. Chailly-Honoré, strongly advocate an oblique incision of abont a third of an inch on the vulva by the side of the perinæum, either to prevent altogether the rupture of that region when much distended, or when the rupture is inevitable, to promote it on a spot where it can produce but little mischief. Both the above accoucheurs support their views by successful cases.

\section{Homceopathic Wrath.}

A physician attached to one of the Parisian hospitals, and who is practising homoopathy, flew recently into a very great 